Jurnal Ilmu Budaya, Vol. 17, No. 2 Februari Tahun 2021

\title{
TABIAT PEREMPUAN DALAM RISALAH KARANGAN ALIM AD-DAHRI
}

\author{
Ridwan \\ Universitas Lancang Kuning \\ Email:uworidwan@gmail.com
}

\begin{abstract}
This analysis analyzes the Malay kitab entitled "Risalah" which is transcribed into Jawi by Ahmad bin Sulaiman Kamal from the original writing in Arabic written by Alim Ad-Dahri. The focus of this analysis is women's characters found in the text. The text conveys ten women characters likened to animals. The knowledge about these women characters assists men to judge before marrying the women since a wife plays important role in determining a good marriage. This analysis qualitative descriptive analysis started with the process of translation from Jawi to the Latin alphabet. This analysis will contribute a lot in choosing a spouse to avoid failure in a marriage. Thus, it is needed to be socialized with the public.
\end{abstract}

Keywords: Risalah, woman characters.

\section{Pendahuluan}

Sastra sangatlah berperan dalam penyebaran ajaran Islam di Nusantara, khususnya masyarakat Melayu. Nilainilai keislaman banyak ditemukan pada teks-teks sastra Melayu. Teks yang dimaksud biasanya dikenal dengan Sastra Islam. Sastra Islam yakni sastra tentang orang Islam dengan amal shalehnya dan dituliskan dalam bahasa Melayu (Fang, 2011: 236-237). Ciri khas sastra Islam itu biasanya beraksara Jawi (Arab
Melayu) dan menggunakan bahasa Melayu. Isi teks biasanya mengenai hubungan manusia dengan Tuhannya, antar sesama dan lingkungan lainya.

Berbicara mengenai isi bahasan mengenai hubungan antara sesama manusia. Keindahan dari sang khalik adalah Ia ciptakan manusia serba berpasangan, jauh-dekat, tinggirendah, susah-senang, lelakiperampuan. Masing-masing saling menutupi kekurangan satu dengan lainnya, sehingga terbentuklah 
kebahagiaan dari hubungan harmonis. Akan tetapi apabila tidak memahami akan kekurangan satu dengan yang lainnya atau tidak seimbang maka akan berakhir kehancuran. Begitu juga di dalam mencari jodoh dalam kehidupan berumah tangga.

Manusia secara umum adalah khalifah di muka bumi di mana tujuan diciptakannya adalah untuk mengabdi pada-Nya di dalam semua hal. Di samping itu juga untuk menjaga kelestarian alam. Maka untuk penjagaan ini manusia membutuhkan teman, yang sekafa'ah (serasi) agar di dalam mengarungi bahtera rumah tangga ke depan bisa menjadi rumah tangga sakinah mawaddah warahmah. Dalam sebuah hadits Rasulullah $S A W$ menyebutkan bahwa wanita adalah tiang Negara, apabila baik wanita maka baiklah suatu bangsa, dan sebaliknya jika jelek maka hancurlah suatu bangsa. Begitu juga di dalam suatu rumah tangga apabila baik wanita pendamping maka baiklah suatu rumah tangga dan juga sebaliknya, maka berhati-hatilah di dalam mencari wanita pendamping untuk berumah tangga.

Panduan mengenai bagaimana mendapatkan pasangan hidup yang serasi untuk kehidupan berumah tangga terdapat dalam dua kitab, yaitu Ar-Risalah dan Taajul muluk. Kedua kitab tersebut diantaranya membahas mengenai tabiat perempuan. Salah satu kitab yang digunakan dalam penelitian ini adalah Ar-Risalah. Isi teks membahas mengenai sepuluh tabiat perempuan yang diserupakan pada hewan dengan merujuk pada Al-qur'an dan Hadist. Diantara ayat Al-qura'an sebagai berikut: "wa-maa kholaktul jinna wal-insya illaa-liya'buduun “artinya" dan tidak kami ciptakan Jin dan Manusia itu kecuali untuk beribadah" ibadah itu meliputi sekalian hal atau aktifitas yang baik.

Kajian dalam kitab ini dimulai pada bab menyatakan sunah-sunah sebelum jamak dengan istri yang diantarkan oleh pemikiran-pemikiran ulama berdasarkan Al-qur'an dan alhadits Rasulullah $S A W$. Dalam teks juga dilengkapi dengan doa-doa di dalam setiap aktivitasnya. 
menerjemahkan, seperti di dalam

\section{Kajian Teori}

Kajian ini mengunakan teori hermeneutik. Secara etimologi, istilah hermeneutik berasal dari bahasa Yunani hermeneutin yang artinya menafsirkan kata benda hermeneia (Sumaryono, 1999: 23). Menurut Palmer (Anshari, 2009), hermeneutik adalah studi pemahaman, khususnya pemahaman teks.

Ditilik dari sejarahnya, hermeneutika diasosiakan dengan dewa Hermes dalam mitologi Yunani. Hermes dihubungkan dengan fungsi transmisi apa yang ada di balik pemahaman manusia ke dalam bentuk yang dapat ditangkap Intelegensi manusia (Palmer, 2003:15). Lanjut Palmer, sekaitan dengan tugas Hermes yang membawa misi dan pesan mulian, yaitu sebagai mediasi dan proses membawa pesan "agar dipahami" memilih tiga bentuk makna dasar dan hermeneuum dan hermeneia dalam penggunaan aslinya, yaitu (1) mengungkapkan kata-kata menjelaskan, seperti menjelaskan sebuah situasi, dan transliterasi bahasa asing (Anshari, 2009).

Objek penelitian merupakan kitab yang termasuk dalam naskah kuno dengan tulisan tangan. Akan tetapi, peneliti hanya mendapatkan fotografi naskah untuk digunakan dalam menganalisis isinya. Penampakan dari hasil fotografi, kondisi fisik naskah dan tulisannya masuk bisa dibaca. Naskah terdiri atas 51 halaman dan setiap halaman terdiri atas 23 baris serta. Pada tiap sudut atas dan kirinya bertuliskan nama kitab menggunakan aksara Jawi yang dilingkari dengan dua garis lurus pada setiap halamannya.

\section{Metode Penelitian}

Penelitian ini bersifat kajian teks sehingga bisa dilakukan dimana saja sesuai keinginan penulis dan pusat utamanya berlokasi di perpustakaan FIB Universitas Lancang Kuning. Penelitian ini dilakukan selama empat bulan dimulai bulan Februari hingga Mei 2020. 
Jurnal Ilmu Budaya, Vol. 17, No. 2 Februari Tahun 2021

Metode yang digunakan dalam penelitian ini adalah metode kualitatif. Adapun rancangan penelitian ini, sebagai berikut: tahap pertama mengumpulkan naskah-naskah yang berkaitan dengan tabiat dan perangai perempuan, tahap kedua mentransliterasikan naskah dari aksara Jawi ke Latin, tahap berikutnya adalah membaca ulang naskah utama dengan menganalisis secara khusus akan manfaat dan dampak negatif dari memilih jodoh serta tahap terakhir adalah penyajian hasil analisis.

\section{Hasil Penelitian}

Manusia diutus Allah SWT sebagai khalifah di muka bumi ini untuk menjaga kelastarian alam, dimana meliputi hewan di udara, darat, laut dan manusia dengan lingkungannya. Hal yang sangat esensial adalah manusianya itu sendiri, di antaranya adalah perempuan. Perempuan disebut baik apabila seluruh aktivitasnya (perangai) juga dianggap baik. Pengertian tabiat menurut Kamus Besar Bahasa Indonesia (Bahasa, 2021) adalah (1) perangai; watak; budi pekerti; (2) perbuatan yang selalu dilakukan; kelakuan; tingkah laku.

Semua orang pasti ingin pasangan berperangai, berwatak serta bertingkah laku yang baik, karena itu akan membawa pada kehidupan sempurna. Pasangan yang serasi adalah dambaan semua orang. Seorang lelaki akan disebut sempurna kalau mereka memiliki pendamping hidupnya begitu juga perempuan. Apabila belum demikian berarti belumlah sempurna kehidupan seseorang. Maka untuk memilih jodoh itu bukanlah hal yang mudah. Pendamping hidup haruslah orang yang betul-betul mengerti akan hal kekurangan dan tabiat kita, begitu juga sebaliknya (QS. Al Haddad: 1350).

Perempuan adalah simbol, seperti hadist Rasulullah SAW yang menyatakan bahwa:

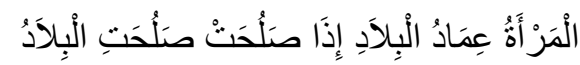

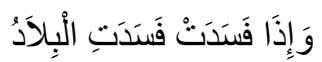

Artinya: Wanita adalah tiang suatu negara, apabila wanitanya baik maka negara akan baik dan apabila wanita rusak maka negarapun akan rusak. 
Lebih jauh dari itu jika perempuan baik, maka baiklah suatu rumah tangga, begitu pula sebaliknya dan bahkan jauh lebih dari itu. Sungguh banyak hadist Nabi Muhammad SAW memuji akan perempuan dan begitu juga sebaliknya.

Wanita sangat berperan dalam kehidupan rumah tangga. Ia mempunyai peran ganda, yaitu mengandung, melahirkan, mendidik, mengasuh dan membesarkan. Sehingga kedekatan seorang anak akan lebih dominan kepada seorang ibu, setiap perbuatan inipun akan dimintai pertanggungan jawab oleh Allah SWT (Amaliyah, 2020).

Bagaimanakah kita bisa menilai, baik dan jahat perempuan? Hal ini penting karena apabila kita salah selangkah dalam memilih, maka akan menuailah, bibit, bobot dikemudian harinya. Perempuan pendamping sangatlah menentukan kebahagian suatu rumah tangga kedepannya. Untuk menjawab teka-teki ini, tentulah sungguh banyak jawabannya, maka dalam ajaran Islam Rasulullah SAW telah membarikan gambaran di antaranya adalah maksud hadist:

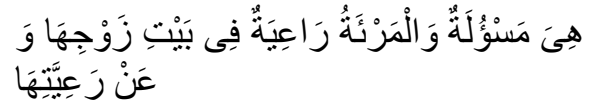

Dan istri adalah pengatur dalam rumah tangga suaminya, dan dia bertanggung jawab atas pengaturannya". (HR. Buchari Muslim).

Berdasarkan tuntunan Hadits Rasulullah SAW di atas, maka penulis akan mencoba memaparkan tentang sepuluh tabiat perempuan dalam teks Risalah karangan Alimud Dahri dan Ahmadil 'Usry yang diterjemahkan ke aksara Jawi oleh Ahmad bin Sulaiman Kamal ra. Pemaparan dimulai dari halaman 12-14 dengan tujuan agar seorang lelaki memiliki modal dan ilmu apabila sudah memiliki keinginan untuk membina suatu rumah tangga.

Isi teks secara umum berisikan sebab kunci utama pembinaaan, kepribadian, watak, tabiat, baik dan buruk, bodoh dan cerdasnya, cacat dan normalnya anak setelah kelahirannnya kelak. Berikut penjelasannya:

Pertama: Perempuan bertabiat Babi 
Tabiaat Babi yaitu tiada ia berbuat baik melainkan makan dan minum memenuhi perut saja dan memecahkan segala bencananya dan mencintacita kemana pergi dan tiada ia mencita-cita akan sembahyang dan puasa dan segala ilmu yang kebaikan tetapi adalah adatnya pada melanggar akan isi rumahnya jua (Dahri:12).

Babi adalah simbol dari jenis hewan yang sangat tamak lagi rakus serta tidak memiliki rasa malu. Memecahkan segala bencana artinya adalah seorang istri yang pada saat suaminya ada di dalam rumah, ia selalu memiliki cara berbuat kegaduhan dengan suami, yang pada akhirnya terjadi pertengkaran hanya disebabkan hal-hal sepele. Ia suka membesar-besarkan masalah, di mana muara dari kejadian- kejadian seperti itu akan berdampak kepada kepribadian anak-anak nantinya. Jadi tidaklah baik jika orang tua terlalu mudah menyalahkan anak jika sikap anak tidak baik seperti suka mendurhaka, kasar, keras dan sadis, sangat sulit dikendalikan. Hal tersebut salah satu penyebabnya adalah karena anak besar dan tumbuh dalam kondisi yang tidak stabil secara syariat, khususnya dari kepribadian seorang ibu dan ayah secara umum. Inilah sejenis hewan Babi sebagai simbol tipe perempuan yang durhaka akan ajaran Allah dan Rasulnya serta senang dan gemar membuat kegaduhan dalam rumah tangganya. Dia akan berdamai hanya jika melihat makanan yang selalu menyenangkan saja.

Kedua: Perempuan bertabiat Kuda

Adapun Perempuan seperti tabiat Kuda, itu gemar memakai seperti yang berwarna merah dan hijau 
Jurnal Ilmu Budaya, Vol. 17, No. 2 Februari Tahun 2021

dan kuning dan tiada ia memakai emas dan perak, dan adalah ia memegahkan dirinya akan suaminya (Dahri:13).

Kuda adalah hewan tangguh dan kuat dan pantang menyerah, adalah simbol seorang perempuan bertabiat kuda ini mempunyai hati yang tegar dan suka berdandan demi suaminya, pekerja keras serta bertalenta di rumahnya. Ia selalu berdandan di depan suaminya.

Ketiga: Perempuan bertabiat Anjing

Adapun Perempuan yang seperti tabiat Anjing itu yaitu tatakkala ia berkatakata dengan suaminya dipalingkannya mukanya dan apabila dikata oleh suaminya suatu kata, dibantahinya serta dengan dihardikkan seperti anjing, apabila dilihatnya harta suaminya dipermuliakan, dan apabila tiada harta suaminya, maka bencilah ia akan suaminya serta dengan cercanya dan berpindahkan ia dari rumahnya (Dahri: 13).
Anjing adalah sejenis hewan yang suka menjulurkan lidahnya, baik disaat ia berlari ataupun dalam keadaan berjalan biasa, serta selalu mengeluarkan air liurnya. Anjing akan selalu mengonggong pada siapapun yang dilihatnya. Akan tetapi apabila datang seorang pencuri, namun si pencuri itu membawa tulang maka diamlah ia serta menikmati tulang tersebut. Itulah simbol wanita yang suka marah dan menghardik suaminya. Apabila terlihat suaminya berharta maka sayanglah pada suaminya dan apabila tidak sungguh bencilah ia dengan menghina dan membentakbentak suaminya.

Keempat: Perempuan bertabiat Begal

Adapun Perempuan yang seperti tabiat Beghal itu apabila bertemu suatu yang 
Jurnal Ilmu Budaya, Vol. 17, No. 2 Februari Tahun 2021

ketakutannya jika dipalu sekalipun nyata dia mau berjalan melainkan hindari jua, dan adalah ia berbaik dirinya, mengelokkan dirinya (Dahri: 13).

Hewan jenis beghal adalah satwa hasil persilangan kuda betina dengan keledai jantan dan merupakan satwa hibrida paling umum kita jumpai. Bagal atau begal dalam Bahasa Indonesia sering digunakan untuk mengangkut barang karena lebih banyak yang tegap membandingkan keledai. Memang ia tidak secepat kuda, artinya perempuan yang memiliki tabiat ini dia tabah menjalani kehidupan yang berat beban, seperti dikala ia bertengkar dengan suaminya, dia sering dipukuli, dihina akan tetapi dia tak jenuh.

Kelima: Perempuan bertabiat Ular

Adapun Perempuan yang seperti tabiat Ular itu yaitu seperti ia dendam dan apabila suaminya jadi berkelahilah suaminya dengan orang yang lainnya (Dahri: 13).

Sifat dan karakter ular memiliki sisi baik dan sisi buruk. Sisi baiknya ia terlihat lembut, pintar dan penyayang. Maka apabila terdengar olehnya orang lain menghina suaminya atau dirinya maka berkelahilah ia demi suaminya itu. Akan tetapi sisi buruknya ia selalu curiga, pendusta, pamanipulatif, licik, bahaya dan posesif.

Keenam: Perempuan bertabiat Kalajengking

Adapun perempuan seperti tabiat kala itu yaitu senantiasa berkeliling (Dahri:13).

Perempuan bertabiat Kalajengking yaitu perempuan yang senantiasa berkeliling rumah orang sekampung serta mengadu- 
Jurnal Ilmu Budaya, Vol. 17, No. 2 Februari Tahun 2021

ngadu serta mengumpat-

ngumpat serta berbantah-

bantah ia dengan mereka itu

seperti kelakuan

kalajengking yang

disengatnya barang yang

bertemu dengan dia dan

tiadalah ia takut akan

bahaya akhirat seperti sabda

Nabi Muhammad SAW: al-

qaatilu laa yad khulul

jannah artinya pemfitnah itu

tidak akan masuk syurga.

Ketujuh: Perempuan bertabiat Tikus

Adapun Perempuan seperti tabiat Tikus itu yaitu pencuri harta suaminya lagi berjual dirinya pada suaminya (Dahri:13).

Tikus melambangkan sosok yang mementingkan diri sendiri atau egois dan serakah. Dikenal hewan yang selalu membawa penyakit. Dan yang paling tidak menyenangkan adalah suka mengambil harta suaminya dan juga suka berjual diri akan suaminya artinya setiap aktivitas yang dia lakukan di rumah tangganya atau buat khusus suaminya, ia selalu ingin dihargai baik berupa uang dan lain sebaginya.

Kedelapan: Perempuan bertabiat Unggas

Adapun Perempuan yang bertabiat Unggas itu yaitu senantiasa ia suka bertudung dirinya dan apabila datang suaminya dari mana engkau, tiada engkau kasih akan daku dan adalah engkau kasih akan perempuan yang lainnya dari pada aku (Dahri:13).

Unggas biasanya memiliki bulu yang menutupi tubuhnya sebagai simbol perempuan suka bersolek dan kebanyakan hewan unggas bernafas menggunakan paru-paru. Umumnya berkembang biak dengan cara ovipar (bertelur) akan tetapi ada sebagian hewan unggas yang memiliki alat bantu 
Jurnal Ilmu Budaya, Vol. 17, No. 2 Februari Tahun 2021

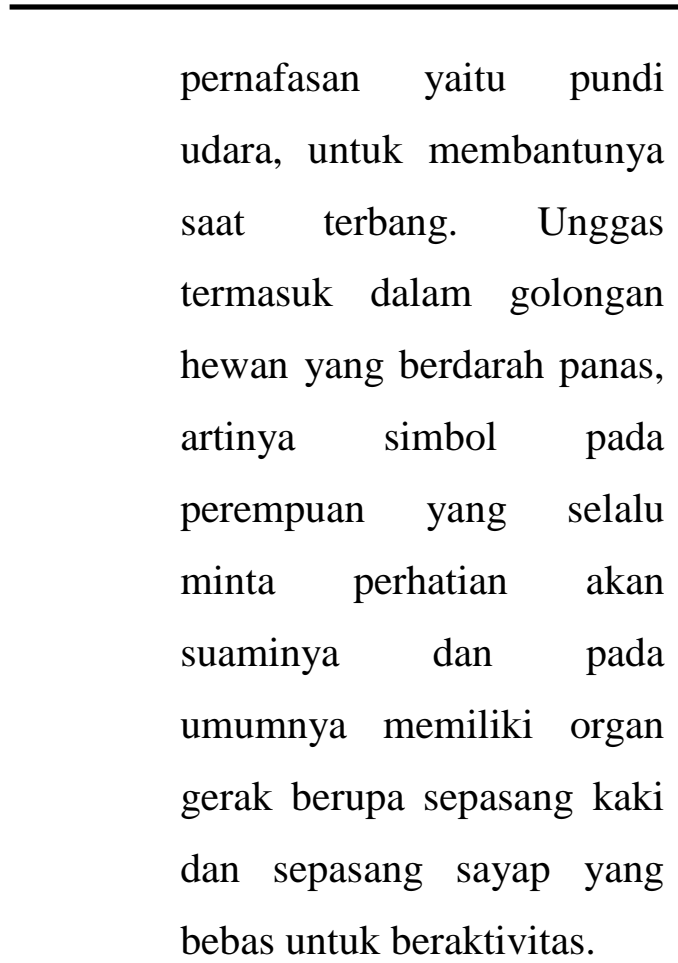

Kesembilan: Perempuan bertabiat Singa

Adapun Perempuan seperti tabiat Singa itu yaitu apabila ada suaminya di dalam rumah maka memulainya perbantahan serta katanya aku seorang diri kau tinggalkan di rumah dengan sakit-sakit engkau pergi bermain-main seorang (Dahri:13).

Perempuan tabiat singa ini membuat suaminya serba salah. Jika suaminya tidak pulang disalahkan dan apabila suaminya di rumah ia selalu mencari celah untuk memulai perkelahiannya dengan bersungut (mengomel) .

Kesepuluh: Perempuan bertabiat Kambing

Adapun perempuan seperti tabiat Kambing itu yaitu perempuan yang sebenarnya adalah padanya beberapa manafaat dan adalah ia perampuan itu shalehah akan mengasihi akan suaminya dan anaknya dan segala orang yang sempurna dan segala keluarganya dan adalah ia berbuat bakti akan Allah SWT dan akan suaminya maka seyogyanya segala hamba Allah SWT perempuan memperangai akan seperti perangai perempuan itu supaya adalah ia beroleh bahagia dunia dan ahkirat (Dahri:14).

\section{Simpulan}

Berdasarkan telaah pada bahasan terdahulu penulis simpulkan bahwa sesungguhnya ibadah itu bukan hanya sekedar melaksanakan ibadah shalat, 
Jurnal Ilmu Budaya, Vol. 17, No. 2 Februari Tahun 2021

puasa, haji, zakat saja akan tetapi juga akan meliputi sekalian hal aktivitas manusia termasuk di dalamnya berumah tangga dan cara mencari pendamping untuk hidup membina suatu rumah tangga. Dalam teks Risalah ini ada sepuluh tabiat perempuan yang diserupakan dengan hewan, antara lain babi, kuda, anjing, begal, ular, kalajengking, tikus, unggas, singa, dan kambing.

\section{Daftar Pustaka}

Alimu, Dahri. Tanpa tahun. Risalah.. Tanpa penerbit.

Amaliyah. 2020. Sekolah Cinta: Indahnya Monogami dan Poligami dalam Islam. Banyumas: Pena Persada.

Bahasa, B. P. 2021. kbbi.web.id. Retrieved February 23, 2021, from kbbi.web.id: https://kbbi.web.id/tabiat.

Depertemen Agama. 2011. Al-qur'an dan Terjemah. Jakarta: Raja Publishing.

Fang, Liaw Yock. 2011. Sejarah Kesusasteraan Melayu Klasik. Jakarta: Yayasan Pustaka Obor Indonesia.

Jalaluddin. 1949. Pertahanan Thariqat Naksabandiyah. Darul Fikri.
Moleong, L.J. 2014. Metodologi Penelitian Kualitatif. Bandung: PT.Remaja Rosdakarya.

Muhammad bin Alwi bin Muhammad Al Haddad. 1350 H. Pengingat Diri. Johor.

Mustofa. 1999. Akhlak Tasawuf. Bandung: Pustaka Setia.

Pradopo, Djoko Rahmat. 2003. Metode Penelitian Sastra. Yokyakarta: Graha Widya.

Sugiono. 2014. Metodologi Penelitian Kualitatif dan $R$ dan $D$. Bandung: Alfabeta. 